\title{
A qualitative study of the impact of electronic journals on scholarly information behavior
}

\author{
Candela Ollé; Ángel Borrego \\ University of Barcelona \\ Faculty of Library and Information Science \\ Melcior de Palau, 140 \\ E-08014 Barcelona \\ (Spain) \\ olle.candela@ub.edu; borrego@ub.edu
}

[To be published in Library \& Information Science Research]

\begin{abstract}
A qualitative study of the impact of electronic journals on the information behavior of academics at Catalan universities shows that academics now read more, and more widely. However, their reading is becoming more superficial; they are compelled to improve their discrimination skills in order to decide what to read in more depth. The electronic accessibility of journals means that academics now make fewer library visits. Web browsing and TOC e-mail alerts are replacing physical browsing, and searching is a very popular option for keeping up to date with developments. Internet search engines, especially Google and Google Scholar, are becoming important sources of information for academics. However, they face problems in managing their personal scientific information.
\end{abstract}

\section{Introduction}

The amount of electronic information available to academic researchers has increased tremendously during the last decade. During this period, accessibility to electronic contents has improved greatly, especially compared to earlier times when most of the information was availably only in printed format. Today, scientists have a wide range of channels through which they can locate and access published literature - bibliographic databases, alert services, hyperlinks, and so on. In this context, it is essential to establish how the increase in the amount of information available and the improvement in its accessibility have affected scholars' information behavior, in order to make suggestions for redefining and adapting the services offered by academic libraries. This task is especially urgent in view of the fact that most of the acquisition budgets of academic libraries are devoted to electronic contents.

\section{Problem statement}

Today, electronic journals are the main channel for the dissemination of scientific information in most disciplines. At the same time, the introduction of new licensing models has significantly increased the amount of information available to researchers. Both the characteristics of the electronic medium and the increase in the volume of scientific information available are affecting researchers' information behavior. So far, however, the question of whether socio-cognitive factors and technical barriers may be affecting the adoption of electronic resources at Catalan academic libraries has not been addressed.

A substantial amount of data on the use of electronic journals is now available, especially compared with the case of printed journals. However, at a time when print 
and electronic journals coexist in academic libraries, usage statistics are still difficult to interpret. Although quantitative studies based on logs and surveys have demonstrated the migration from print to electronic sources, additional qualitative insights into the information-seeking behavior of scholars are needed. Previous work suggests that the use of mixed quantitative and qualitative methods provides a deeper understanding of the phenomenon under study (Fidel, 2008). The present study, based on self-reported behavior by academics, aims to fill this gap and to provide new insights that will be useful to academic libraries and publishers aiming to improve their collections and services and, especially, in order to improve the technological platforms that make electronic contents available. Specifically, the study addresses the issue of how the increase in the number of electronic journals available has modified academics' information behavior, on four fronts: the amount of their reading, the diversity of sources consulted, ways of keeping up to date, and the personal management of scientific information. The results of the study highlight the effects of electronic journals on the information behavior of Catalan researchers, and have practical implications for academic libraries wishing to optimize the allocation of resources for acquisition of electronic resources. Better allocation of funds is essential at a time of increasing spending on electronic resources and growing financial restrictions. Contrary to expectations, perhaps, electronic resources do not save money but actually involve additional costs such as hardware, software, telecommunications, training and so on. Better allocation is critical to provide the best possible service and to address conflicts deriving from the seemingly limitless demands of users competing for scarce funds.

\section{Literature review}

The key changes introduced by the shift from a scholarly communication model based on print journals to another based on electronic resources have been studied in depth during the last decade. This review concentrates on two aspects of this phenomenon: the migration from print to electronic journals, and its impact on academics' information behavior.

\section{Migration from print to electronic journals}

The first studies carried out during the 1990s made it clear that electronic journals are here to stay. In an exhaustive review of the literature, Tenopir (2003) analyzed the results of over 200 studies of the use of electronic resources in libraries published between 1995 and 2003. The main conclusion of her review was that electronic resources had been rapidly adopted in academic spheres, though academics' behavior tended to vary according to discipline.

This rapid transition from print to electronic journals has been described in several settings. Chrzastowski (2003) showed that, in 2002, print journals represented only 6\% of all uses at the University of Illinois Library at Urbana-Champaign. The data were conclusive enough to state that, more than a migration, it was a "stampede". At the Duke University Chemistry Library, Vaughan (2003) showed that between 1999 and 2001 the use of print journals almost halved. What is more, the journals that were available only in print were used less - indicating that format is a key element when deciding on access to information.

Longitudinal data compiled at the University of Illinois at Chicago Library (De Groote and Dorsch, 2001; De Groote, Shultz and Doranski, 2005; De Groote, 2008) suggested a different conclusion, that is, that print journals may continue to be widely used even 
after the introduction of electronic journals. Similarly, Siebenberg, Galbraith and Brady (2004) reported that most print journals were used more at the time of their study than prior to the advent of electronic journals at Washington State University. The authors contended that migration from paper to electronic journals depended on the subject area and that quality and pertinence remained the dominant factors in users' choice of journals. However, in a later study in the same setting to assess whether the increase in the use of paper was continuing, Brady, McCord and Galbraith (2006) observed a cultural shift between the two studies, reporting that $94 \%$ of all journal use was now via electronic format.

In addition to these studies based on data of use and citations of print and electronic journals, other researchers have directly surveyed academics. They find that scholars, especially those in the sciences, have enthusiastically embraced the use of electronic journals. Bar-Ilan, Peritz and Wolman (2003) reported a high degree of acceptance of electronic journals at seven Israeli universities, although disparities were found between disciplines and ages. Later, Bar-Ilan and Fink (2005) found that more than $80 \%$ of the scholars at the Science Library of the Hebrew University frequently used (and stated a preference for) electronic formats irrespective of their rank and age. Similarly, Connell, Rogers and Diedrichs (2005) found extensive use of electronic journals, especially in the sciences, in a survey of users at Ohio State University. Another survey among faculty at Istanbul University (Dilek-Kayaoglu, 2008) showed again that most researchers supported the transition from print to electronic format, especially in the natural sciences. The major deterrent to the use of electronic journals was the lack of subscriptions in the particular academic's field.

Impact of electronic information resources on information behavior

Aside from the transition from print to electronic journals, other studies have centered on how the adoption of electronic information resources, mainly electronic journals and databases, has affected academics' information behavior. In one of the first studies that adopted this focus, Eason, Richardson and Lu (2000) determined that contents and ease of consultation were the most significant factors affecting patterns of use. Also, Eason, $\mathrm{Yu}$ and Harker (2000) reported that basic browse, print and search were the core functions most valued by users. Similarly, a survey of Dutch faculty performed by Voorbij and Ongering (2006) concluded that researchers prefer searching to browsing in order to track down relevant articles.

Brennan et al. (2002) adopted a qualitative focus in order to explore the habits of early adopters of electronic journals at the University of Illinois at Chicago. Their results showed that faculty visited the library less often and read more than in the print era across a broader number of journals. Most participants reported using generic databases while a few relied on smaller discipline-specific databases. Davis (2004) reached a similar conclusion using a different approach; studying referral URL data to analyze how academics at Cornell University access electronic journals published by the American Chemical Society he found that, although the majority of referrals came from established tools - such as library catalogues, library e-journal lists and bibliographic databases - a substantial number of referrals originated from generic web searchers, mainly Google.

The Ciber group based at University College London has carried out extensive research on the topic. Based on results of deep log analysis, Nicholas, Huntington and Watkinson 
(2005a) characterized the behavior of most users as that of "bouncers" or "checkers", who either obtain what they want or leave after a brief visit. They also found very little use of added-value functionalities such as search engine, profiling, email requests for articles and pop-ups (Nicholas et al., 2006a). Another analysis of journal usage on OhioLINK (Nicholas et al., 2006b) showed the immense popularity of the search engine among users compared with alphabetic or subject lists of journals. Further research into the role of abstracts in the digital environment (Nicholas, Huntington and Jamali, 2007) showed their wide acceptance as a means of identifying relevant literature. Further research (Nicholas et al., 2008) showed a great deal of variety among scholars in their full-text viewing habits; a large proportion of views were highly cursory in nature, and articles were viewed for very short times.

Similarly, reviewing the literature on electronic journal users' behavior, Rowlands (2007) concluded that scientists read more and more primary journal materials from a wider range of sources, but they spend less time per article reading and use fewer specialist secondary services. Electronic versions have rapidly displaced print journals, with convenience and digital visibility being critical factors in the new information landscape.

The present study expands on previous research into the impact of electronic journals on the information behavior of academics at the universities that are members of the Consortium of Academic Libraries of Catalonia (CBUC). The CBUC comprises the eight public Catalan universities and the National Library, and it allows other institutions to participate as users. In an initial study based on statistics of use of electronic journals licensed by the CBUC during the period 2000-2003 (Urbano et al., 2004), the results showed a huge increase in the number of journals available thanks to consortial licenses, a constant increase in the number of articles downloaded during that period, and a wide use of journals not previously subscribed. A second study, a quantitative survey of the academic staff at the universities belonging to the CBUC (Borrego et al., 2007a), showed a high level of familiarity with, and extensive use of, electronic journals among academics. However, this behavior was highly dependent on age and discipline, with younger scholars and those working in sciences being the most active users.

\section{Procedures}

A qualitative design was aimed to obtain an in-depth understanding of academics' behavior in relation to electronic journals. In the first stage of the project, an open-ended questionnaire was sent by e-mail to a sample of academics at the universities that are members of the CBUC. To complete these data, personal interviews were performed with a sample of eleven informants taken from the participants in the previous stage.

\section{Open-ended survey}

In the first stage of the project, data were compiled through an open-ended questionnaire sent by e-mail to a sample of scholars at Catalan universities. Meho (2006) described the advantages of using e-mail interviewing in qualitative research, a method that can provide quick, convenient, inexpensive and high quality data.

The subjects surveyed were identified through a prior quantitative survey (Borrego et al. 2007a) in which participants were asked to supply their e-mail address if they wished to participate in a subsequent qualitative survey. A total of 553 participants provided e- 
mail addresses, although 16 of these were illegible and unusable. Thirty surveys were sent out in mid-November 2007, asking if participants had problems with the wording of the questions. At the end of November, all the remaining questionnaires were sent. Two reminders were sent in December to the academics who had failed to return the questionnaire. Forty-seven surveys were not delivered due to incorrect e-mail addresses. In the end, 137 surveys were returned and analyzed. Responses to the survey were categorized in patterns as the primary basis for organizing and reporting the results.

The return rate (28\%) was considered low and limits the representativeness of the results for the whole population. However, the number of respondents can be considered sufficient for a qualitative study. Probably the reason for the low return rate lies in the characteristics of the survey, since open-ended questionnaires require more effort from the interviewee than closed-ended questionnaires, and the non-response rate is likely to be higher.

The survey was preceded by a presentation text indicating the aims of the study and the process for answering and returning the questionnaire. The survey was selfadministered, as the researchers did not participate. This approach has the limitation that some of the questions may not be understood or the answers may be incomplete. However, it offered the opportunity to contact a higher number of people than if personal interviews had been performed, and also offered more confidentiality. In addition, more in-depth personal interviews were conducted at a later stage of the project.

As already stated, the study used a qualitative design. The sample was small but focused, rather than quantitatively representative. However, the sample included academic staff with diverse ages and disciplinary backgrounds, as shown in Table 1.

Table 1. Profile of respondents to the e-mail survey by age and discipline

\begin{tabular}{|l|c|l|c|}
\hline \multicolumn{1}{|c|}{ Age } & \multicolumn{1}{c|}{$\begin{array}{c}\text { Number of } \\
\text { respondents }\end{array}$} & \multicolumn{1}{c|}{ Discipline } & $\begin{array}{c}\text { Number of } \\
\text { respondents }\end{array}$ \\
\hline Under 30 & 10 & Biomedicine & 38 \\
\hline $31-40$ & 47 & $\begin{array}{l}\text { Exact and natural } \\
\text { sciences }\end{array}$ & 36 \\
\hline $41-50$ & 44 & Social sciences & 36 \\
\hline $51-60$ & 27 & Engineering & 10 \\
\hline Over 60 & 9 & Humanities & 17 \\
\hline Total & $\mathbf{1 3 7}$ & Total & $\mathbf{1 3 7}$ \\
\hline
\end{tabular}

Interviews

In the second stage of the project, eleven of the subjects who had responded to the email survey were personally interviewed by one of the researchers. Previous research in the same setting (Borrego et al., 2007a) showed a high level of familiarity and extensive use of electronic journals among academic staff. This behavior seemed to be closely related to age and discipline, with younger scholars and those working in the sciences being the more active users. Consequently, these two variables - age and discipline were considered with particular care in the selection of the interviewees. Table 2 shows the characteristics of the eleven interviewees by age and field of knowledge. Additionally, scholars from six of the universities in the CBUC were interviewed. After 
applying these three criteria, the eleven subjects to be interviewed were selected from among the respondent scholars who had provided the most detailed information in the open-ended questionnaire. The interviews explored three topics: use and assessment of the library, access to electronic information, and impact of electronic information resources on information behavior. All interviews ended by asking the subject for three suggestions on how access to scientific information could be improved.

Table 2. Characteristics of interviewees by age and discipline

\begin{tabular}{|c|c|l|}
\hline & Age & Discipline \\
\hline 1 & 48 & Journalism \\
\hline 2 & 61 & Nutrition \\
\hline 3 & 43 & Audiovisual communication \\
\hline 4 & 33 & Social science education \\
\hline 5 & 38 & Education \\
\hline 6 & 41 & Physics \\
\hline 7 & 67 & Archeology \\
\hline 8 & 28 & Applied mathematics \\
\hline 9 & 32 & Human motor development \\
\hline 10 & 56 & Biochemistry \\
\hline 11 & 29 & Physiotherapy \\
\hline
\end{tabular}

All interviews were recorded at the university offices of the interviewees and lasted between forty-five and sixty minutes. All participants were asked to sign an informed consent sheet which described the aim of the interview and its procedures, guaranteed anonymity, and provided the e-mail addresses and telephone numbers of the researchers.

\section{Results}

Amount and sources of reading in the electronic environment

First, the academics were asked how the increase in journal availability and accessibility had affected their information behavior. Almost unanimously, the interviewees reported that there had been positive changes, thanks to the increase in the number of journals available to the efficiency and convenience of the process. A 49-year-old biochemistry professor summarized many of the advantages of electronic journals:

"[The availability of electronic journals has affected me] very positively. I can consult bibliographic materials quickly and efficiently, with no time pressure, whenever it suits me, in the comfort of my office.”

About three quarters of the survey respondents stated that they consult more journals and read more articles than they did in the past. Since the number of journals available has increased and access is so much easier, researchers are reading more from a wider range of journals.

"I now consult journals that were previously inaccessible or unavailable at my library. That means I can browse more sources. I also have a wider selection of choices when searching for articles I'm required to read." (age: 48, discipline: communication studies). 
"Due to the increase in availability [of electronic journals], I often read journals that I used to have to consult physically in the library or for which I had to request offprints directly from the authors.” (41, medicine).

The increase in the range of journals read seems to be a direct consequence of the increase in the offer by the library, but no one attributed the increase in the diversity of sources to an increase in interdisciplinary research that would require scholars to obtain articles from sources in different fields.

When the academics surveyed were asked whether they systematically browse new issues of a core set of journals, a dozen responses illustrated a well-established phenomenon: as library patrons obtain remote access to a broader range of electronic materials, their library visits decline. Even the researchers who stated that they consult books reported that they visited bookstores more frequently than libraries, and several interviewees stated that they tend to buy those books they need for academic purposes. Three subjects stated that they hardly ever set foot in the library. Although it was expected that the decline would affect academics in the sciences most severely, in fact it seems to affect researchers in all disciplines. An academic in Humanities made this illuminating comment that quantifies a drastic reduction in library visits:

"I [...] have reduced my visits to the periodicals library from approximately twice a week to once a semester.” (40, Galician language and literature).

When questioned regarding the benefits of electronic access the interviewees stated that speediness and convenience of electronic access meant that they have more reading time and, more generally, more time for doing research. However, the increase in the number of articles and journals read carries a price: in general, the academics surveyed note that their reading is becoming much more superficial.

"My range of sources has increased and I read more articles, although perhaps in less depth.” (48, physiology).

"Obviously, the increase in availability and especially in accessibility means that much more information can be consulted than ever before. However, since the number of hours in the day hasn't changed, reading tends to be much more superficial.” (46, botany).

The decrease in reading depth leads to discontinuous, quick, skim reading, although just one academic mentioned the use of text searching facilities for finding keywords inside the articles. At the same time, the increase in information availability requires a greater degree of discrimination in order to select what to read in more depth:

"I consult more journals and browse more articles, but I don't spend much more time reading. I’ve become more discriminating." (47, civil law).

Academics realize that they have access to a much wider range of publications than in the past. Academics at smaller universities were especially aware of the dramatic increase in the number of journals available. However, many scholars did not seem to be fully aware that this is the result of consortial licensing agreements signed by the CBUC: some of the survey responses and, especially, further comments by one 
interviewee suggested that they thought that the increase in availability stemmed from lower electronic journal prices, or even from free access.

"I consult many more journals and articles. At small universities, where periodical libraries are not particularly large, access to electronic journals is essential.” (43, mathematics).

“The increased availability of scientific journals has opened up a lot of doors for researchers [...]. In the past, library budget cuts reduced the number of journals available. Access to digital formats means that opportunities have grown exponentially.” (41, financial accounting).

Access to electronic resources from academics' desktop computers thanks to IP recognition is so transparent that many users are not fully aware that access is possible because of institutional subscriptions. As explained below, many scholars refer to subscribed electronic journals via Internet search engines; most users are unaware of the fact that access is brought by their university, even though this circumstance is explicitly stated by the publishers. For instance, one interviewee welcomed "the increase of access to open access journals" when he actually meant the increase in subscribed contents.

Although open access was not specifically the topic of the study and it was not mentioned by the researchers either in the survey or in the interviews, several scholars brought up the subject; they seemed quite interested in the topic although a certain degree of confusion was detected.

The increase in the amount of articles and range of journals read has become widespread among all disciplines. Only one scholar in Contemporary History stated that he did not use electronic journals at all and relied exclusively on print journals and books. Another researcher who reported that he consulted a very limited number of journals in a highly specialized field said that his behavior had not changed as a result of increased information availability.

"[It has affected me] very little, actually. The scope of my research field is very limited. At most, there are only five or six journals that publish truly relevant material, and they're the only ones I read regularly.” (35, mathematics).

One academic stated that accessibility to electronic journals meant that, to some extent, he now ignored print journals. A few scholars also admitted consulting electronic articles that they would ignore if more effort was required to consult them. However, when explicitly questioned on this topic all eleven interviewees stated that they were willing to wait for articles that really interested them even if the interlibrary loan system was slow.

Strategies for keeping up to date

When academics were asked how they keep up to date with developments in their fields, three strategies emerged: web browsing of journal issues, database searches, and TOC e-mail alerts. Obviously, these strategies are not mutually exclusive and most academics use a combination. 
As print journals progressively disappear from library shelves, physical browsing is being abandoned, although a number of academics (fewer than ten in our sample) continue to receive print journals, via personal subscriptions or editorial board memberships, and physically visit libraries to browse new issues. Most subjects appeared to have translated physical browsing into web browsing, and stated that they systematically consult the latest issues of selected journals from the publishers' web sites. For instance, one researcher mentioned that his rudimentary control method consisting in keeping a file in which he made a note of the last issue he had reviewed. Not surprisingly, when scholars named the journals they browse systematically, Nature, Science and annual review series were the most frequently mentioned sources.

In general, browsing is being replaced by TOC e-mail alerts that derive from a variety of sources: journal publishers, university libraries, Thomson Reuters (ISI) databases, bookstores in the case of books, etc.

As expected, some academics use more informal ways for staying up to date, such as conversations with colleagues, attending conferences, periodical searches performed by research assistants, and so on. In general, peer-to-peer communications have been strengthened by the Internet, as it enables academics to visit colleagues' websites. One academic in communication studies mentioned using a wiki with his research group. Blogs, however, were not specifically mentioned by any of the respondents.

"I have four ways [of keeping up to date]: talking to other researchers, attending conferences, reading leading researchers' websites and searching Google Scholar.” (28, applied mathematics).

"I mainly use the Internet [to keep up to date]. From time to time, I visit the websites of prominent researchers working in my field. I also consult the latest issues of the leading journals.” (50, philosophy).

More than $90 \%$ of the surveyed academics reported conducting database searches. In fact, a couple of scholars reported that they have definitively abandoned browsing and rely exclusively on database searches. Google and Google Scholar were explicitly cited by nearly a quarter of the sample although no specific databases or search engines were mentioned in the survey. Indeed, for many researchers, these tools have begun to supplant traditional indexing and abstracting (I\&A) databases. Academics not only use Internet search engines but are very happy with them. One academic described Google Scholar as "fantastic". Two interviewees also mentioned using the Google images search engine in order to retrieve visual material for teaching purposes.

Very few answers explicitly mentioned the names of databases consulted except for the case of ISI Web of Knowledge - all the universities surveyed have access to this resource - PubMed, and a very strong use of SciFinder by chemists. A number of academics also mentioned large publisher platforms such as ScienceDirect. Some individual scholars mentioned databases specialized in their subjects: ERIC for education, MLA for language and literature, and so on. However, even when these resources were mentioned they were frequently a second source after Google:

"First, I search my own database, which is usually sufficient since it is quite large. I then do a simple search in Google or Google Scholar. After that, I search 
PubMed and SciFinder Scholar. For books, I use search engines such as BookFinder or the US Library of Congress.” (61, nutrition).

“On a few occasions, I've searched the databases of certain publishers (Elsevier or Wiley, for instance), but I normally use Google as my primary source.” (43, information technology).

"I search Google and then I refine with Medline." (42, biochemistry).

Fewer than five respondents reject database searches as ineffective. Finally, just a couple of respondents mentioned searching digital repositories such as arXiv.org, TDX, a CBUC dissertations archive, and Recercat, a CBUC preprint archive.

\section{Use of personalized information services}

When academics were asked if they used electronic personalized information services, around a third of the answers were negative. Nearly all of the respondents who reported making use of them mentioned TOC e-mail alerts, while fewer than five mentioned using RSS feeds provided by publishers and keyword or citation alerts.

Most of the respondents who do not use these services stated that they are bombarded with messages that they do not have time to read. Consequently, they do not feel that personalized information services are very useful; they prefer to conduct searches when they actually need information.

"I used to use [personalized information services], but now I use them much less often. I unsubscribed to several of them because the volume of information was simply overwhelming. Now I just search for what I need and that works out fine.” (45, political science).

"I'm using them less and less often because the range of journals is very wide and sometimes you can find interesting articles in journals that are not directly related to the topic at hand or in which you don't usually search for articles on a specific topic.” (40, business administration).

Although some of the responses reported that they receive too much information, very few respondents ask the library for help in order to filter it. Just a couple of respondents said that they asked librarians for help in performing searches, or had defined a profile in order to receive information filtered by a professional.

With a very few exceptions, scholars do not seem overwhelmed by the great amount of electronic information available. They experienced problems in the past when access to information was much harder, and they regard the greater access to electronic information as a real gift. Several researchers acknowledge that they are not able to monitor all the relevant information in their field, but they do not seem to be particularly worried about this. Only one interviewee explained a personal experience of three researchers independently searching for references for a research project and obtaining totally different results; she feared that in evaluation processes she would be accused of not being aware of important contributions in her field. 
Scholars think that the increasing amount of published information is not always justified, but generally they accept this as inevitable: they are aware that evaluation procedures require scholars to publish more and more and that this is the cause of the publication inflation to which they themselves contribute.

Determining the value and interest of an article

Not surprisingly, "content" is the key criterion when determining the value and relevance of an article. Expanding on this answer, academics stated that they tend to skim-read the article in order to decide whether it merits more detailed reading. This confirms the point mentioned above that academics do a large amount of superficial reading, probably in order to decide what to read in more depth.

About half of the academics surveyed stated that they rely on the abstract and/or on the author's background information (name, affiliation, status, etc.) to determine the value and relevance of an article. These two comments illustrate this behavior:

"I use two criteria: the author (and any reference material I have on the author) and the abstract. If I do not have any reference material, I usually just skim the article.” (33, social science education).

"[I determine value and relevance] based on the following criteria: name, educational background and prestige of the author; information from the abstract; keywords; title of the article; reading over the conclusions; and reading the entire article, which is the definitive criterion.” (44, medieval history).

One academic felt that relying on prior knowledge of authors may be inadequate:

"I determine the value of an article based on the authors and the research group they belong to. Maybe this isn't quite fair, because good articles are sometimes written by inexperienced researchers or research groups.” (55, medicine).

Several interviewees mentioned the author not only as a key criterion for deciding the value and interest of an article, but also as a frequent criterion for searching.

Other criteria mentioned included the prestige of the journal in which the article was published, colleagues' recommendations, the methodology used, figures, and so on. Two academics in Biochemistry and Molecular Biology, and Physiology mentioned using Faculty of 1000 - a bibliographic database in Biology and Medicine in which articles are evaluated by experts in the field - as a source. However, not all the universities surveyed subscribe to this resource.

\section{Personal information management techniques}

The respondents were also asked about their information management techniques. In general, this is an area that poses problems for academics; they themselves describe their techniques as "primitive" or "rudimentary". There are three main groups: 1) those who continue to use the traditional method of folders (now electronic folders); 2) those who use some kind of bibliographic management software; and 3) those who use no information management system at all. 
The first case comprises around half of the sample and includes academics who have transferred their experience of archiving printed articles in folders to the electronic environment. In general terms, they are aware of the problems: as the amount of information increases it is more difficult to find a document, many articles are duplicated in several folders, and so on. Some academics still keep paper file systems, although most introduce the references of the articles in a word document or in an excel worksheet along with the links to the full-text of the documents that are locally stored. Most scholars keep paper files of print articles and electronic versions of articles published in electronic journals. A couple of researchers, however, reported scanning print articles in order to file them along with electronic files.

Although most scholars reported organizing information by subject, a few said that they organize their sources in folders that correspond to the articles in which these sources are cited. The response below is a typical example of an academic who has made a slight transition from paper to electronic archives and who is aware of his information management problems:

"I compile information on new developments in a word processing document. I file the full text versions in folders for future reading. I also save various links. I have to develop a better information management system because sometimes I get snowed under and I have problems locating relevant documents.” (40, education).

A couple of academics stated that they have abandoned the folder system because it is easier to search for an article again in the original source. Others have begun using bibliographic management software. About a quarter of the sample mentioned software packages, including commercial software such as RefWorks, Endnote or Reference Manager and open source software such as JabRef. Additionally, a few academics reported using general database management software not specifically designed for managing bibliographic references, such as Access or FileMaker.

"Until a few years ago, I filed the paper copy. I subsequently started filing the first page only, and then the PDF. I recently started using Reference Manager.” (54, toxicology).

"[I use] Endnote and a desktop folder in which I keep the PDF files of the articles. Endnote links each record with the PDF. If I write any comments on the hard copy (while traveling, for instance), then I scan the article. I also make digital annotations using Acrobat editing tools.” (31, computer science).

Finally, a quarter of the respondents stated that they did not use any kind of reference management system at all. Some of them seemed unaware of the software available. Those who are familiar with the software (some of whom have even attended courses in its use) maintain that it involves an excessive amount of work in view of the benefits they can derive from it. In fact some of the answers reveal that they are not fully aware of the possibilities of this software. For instance, one respondent justifies not using reference management software because each journal asks for a specific bibliographic format when this is precisely one of the advantages that this software offers. 
“I don’t use software such as Refworks, EndNote or similar programs, nor do I use a simple database management system such as Access. I know I should, but the time required tocreate the databases acts as a deterrent. I could probably recoup the time investment, but for now, I don't see the point or feel that the time savings would be that significant.” (33, social science education).

"I don't use any software programs because I'd have to enter the citations beforehand and I just don’t have the time.” (48, physical chemistry).

Even the scholars who seem to have a deeper knowledge of reference management software complain that exporting and creating bibliography options does not always work well so they have to correct the references manually.

A blank space was provided at the end of the survey for suggestions and further comments. In the interviews the academics were also asked for suggestions on how to improve access to scholarly electronic information. Most of the sample did not take advantage of this opportunity and, when they did, it was in order to ask for more subscriptions to resources, although the survey was not sent by the library. At this point, some researchers expressed some envy in relation to the resources available at other universities in the Consortium. Some complained that they did not have access to resources that were available to their colleagues at neighboring universities sometimes just a few miles away. On the other hand, all eleven interviewees expressed their high opinion of the staff and services offered by their academic libraries, especially in relation to the increase in journal library collections.

The main complaint was related to the diversity and complexity of the search interfaces academics have to consult. Although the CBUC offers a federated search engine and link resolver, many scholars seem unaware of this option and search individual databases. They ask for more intuitive screens, larger font sizes, fewer clicks in order to access the information, more colors to distinguish between different kinds of materials, and so on. Academics also complain about the difficulties in interpreting the information regarding the availability of specific issues and numbers of subscribed journals. One interviewee compared the library catalogue to Google in order to highlight the catalogue's lack of relevance ranking. As a result, a number of scholars bypass library finding tools and search Google in order to retrieve library-subscribed contents.

\section{Discussion}

As a consequence of the increase in availability and accessibility of electronic journals at Catalan universities, academics have increased the amount of articles and the range of journals they read. The results of our study are coincident with those found over a period of many years by King and Tenopir, whose regular surveys of US scientists have shown a constant increase in their reading (King and Tenopir, 1999; Tenopir and King, 2002; Tenopir and King, 2008).

The increase in the amount of information consumed is explained, first and foremost, by the increase in availability. In 2003, the six consortial licenses signed by the CBUC allowed Catalan universities access to 1,398 journals, representing an increase of 980 journals for the library that had previously had the largest collection and 1,366 journals for the one with the smallest (Anglada, 2003). In January 2009 the CBUC offered 
access to 10,600 journals. The results indicate that there is a high level of elasticity in information usage among scholars: as they gain access to more journals, they tend to read more. However, as some of the participants pointed out, days continue to have 24 hours, and so their reading is becoming more superficial. In fact, according to Tenopir and King (2008), scientists reported spending an average of 31 minutes per reading in 2005, down from 48 minutes in 1977. At the same time, they have been compelled to improve their discrimination skills in order to decide what to read in depth.

The speed and convenience of the electronic accessibility of journals allows scholars to save time on physical library visits, time which they can invest in carrying out more research. The decline in the use of academic library collections and services was described by Martell (2008). However, more research is needed to determine how the increase in the amount of information offered by the library and the time saved thanks to electronic accessibility is improving the amount and quality of the research produced by Catalan academics.

As indicated, not only the amount of articles read has increased, but the range of sources from which these articles derive as well. This increase is explained, in the first place, by the increase in the number of journals available. Another reason is to be found in the changes in information-seeking patterns. Our results show that, as print journals disappear from library shelves, web browsing and TOC e-mail alerts are replacing physical browsing. Other options, such as RSS feeds, do not seem to be widely used. TOC e-mail alerts allow scholars to receive alerts from a larger number of journals than would have been possible in the print journals era. Searching is another popular option for keeping up to date. This strategy increases the visibility of materials and the chances of serendipity as there are more options for discovering more articles from a wider range of sources, as Nicholas et al. (2005b) have also shown.

Serendipity is also increased by the fact that a number of scholars prefer to search thematically generic databases and Internet search engines. Although it might be hypothesized that this trend towards search generic sources might be related to an increase in interdisciplinary research, as suggested by Voorbij and Ongering (2006), no evidence to support this view has been found.

Our results show that Internet search engines, especially Google and Google Scholar, are now among the most important sources of information for academics. Indeed, for many researchers, these tools have begun to supplant traditional indexing and abstracting databases. Scholars value these tools highly due to their speed and relevance ranking. The use of digital repositories was mentioned occasionally, although the use of Internet search engines could improve the chances of retrieving documents from these sources.

As already mentioned, TOC e-mail alerts are the main (and almost the only) added feature of publishers' platforms that scholars use. Similar results have been reported by Nicholas et al. (2006a). It may be that these services are not widely used simply because academics are unfamiliar with them. However, several of the academics stated that they do not use them because they feel bombarded with messages that they do not have time to read; they do not feel that these services are useful and prefer to conduct searches when they actually need information. 
When asked how they determine the value and relevance of an article, most academics stated that they rely on the abstract and on the author's background information. The popularity of abstracts - a type of content that is usually offered for free in publishers' platforms - is not surprising. An earlier study of the consumption of electronic journals of the American Chemical Society at the University of Barcelona (Borrego and Urbano, 2007b) had already shown their popularity and the usefulness of this variable for determining the number of regular users of a journal.

Our results show that information management presents many problems for academics. They themselves are aware of this and describe their techniques as "primitive" or "rudimentary". Although some scholars use some kind of bibliographic management software, most of them continue to use the traditional method of folders or simply do not use any information management system at all, searching for the same information every time they need it. Interestingly, the academics who use some kind of reference management software mentioned using a wide arrange of products. However, all the respondents enjoy a consortial license of RefWorks. The results support the idea that they do not think that this particular software is unsuited to their needs, but simply ignore this option and buy other software, presumably through research grants.

Users are highly satisfied with the range of electronic products and services that their libraries provide for them. However, it is also true that a number of researchers seem unaware that most of the electronic resources they consult are only accessible thanks to institutional subscriptions. The transparency in electronic accessibility of information and the fact that the physical library has disappeared from the life of many scientists has led some of them to forget its importance in providing access to electronic resources. Although scientists are well aware of the costs of their research investments which they pay by means of grants — such as equipment, software or staff — information is usually provided to them at no direct cost, and some of them have the impression that it is provided for free. Finally, most academics express a high opinion of academic libraries' staff and services and most complaints refer to the diversity and complexity of search interfaces.

\section{Conclusion}

The increase in the amount and accessibility of the information available has led to an increase in the amount of journals and articles read. The consortial decision to provide library users with more information has been successful; users now make extensive use of the new sources available and express a high degree of satisfaction with the range of products and services on offer. There is a high level of elasticity in information usage, with more content provision leading to more consumption. Convenience is an essential element when accessing electronic information; scholars may think that, in some instances at least, articles that are hard to find can be substituted by more accessible articles. As a result of the increase in information consumption, reading is becoming more superficial, so full text is often downloaded just in order to determine what to read in more depth. In this regard, the qualitative insights obtained through this research will aid the interpretation of regularly compiled quantitative usage data on the use of electronic journals.

The information-seeking behavior of scholars is changing in the electronic environment. Web browsing, TOC e-mail alerts and searching have become the most popular options for keeping up to date. The variety in the origins of the literature consulted indicates that 
functionalities for accessing electronic resources work well. However, the preference for Internet search engines and the criticism of the complexity of traditional bibliographic tools reflect users' preference for a single point of access to the electronic collection and the failure of the library to provide users with a single interface for all the information it storages. Further research is needed to determine the extent to which the recent consortial acquisition of a federated search system is fulfilling users' demands, and should also focus on specific subject domains to encourage the design of tools in added-value facilities in different disciplines.

\section{Acknowledgements}

Support for this study was provided by the Spanish Ministry of Science and Innovation (CSO2008-04762/SOCI).

\section{References}

Anglada, L. (2003). Impacte i influència dels consorcis en la gestió de les col-leccions. BiD: textos universitaris de Biblioteconomia i Documentació, 10. Retrieved December 10, 2008, from: http://www.ub.es/bid/10anglada.htm.

Bar-Ilan, J., \& Fink, N. (2005). Preference for electronic format of scientific journals A case study of the Science Library users at the Hebrew University. Library \& Information Science Research, 27, 363-376.

Bar-Ilan, J., Peritz, B.C., \& Wolman, Y. (2003). A survey on the use of electronic databases and electronic journals accessed through the web by the academic staff of Israeli universities. Journal of Academic Librarianship, 29, 346-361.

Borrego, A., Anglada, L., Barrios, M., \& Comellas, N. (2007a). Use and users of electronic journals at Catalan universities: The results of a survey. Journal of Academic Librarianship, 33, 67-75.

Borrego, A., \& Urbano, C. (2007b). Analysis of the behaviour of the users of a package of electronic journals in the field of chemistry. Journal of Documentation, 63, 243-258.

Brady, E. E., McCord. S. K., \& Galbraith, B. (2006). Print versus electronic journal use in three Sci/Tech disciplines: The cultural shift in process. College \& Research Libraries, 67, 354-363.

Brennan, M. J., Hurd, J. M., Blecic, D. D., \& Weller, A. C. (2002). A snapshot of early adopters of e-journals: Challenges to the library. College \& Research Libraries, 63, 515-526.

Chrzastowski, T. E. (2003). Making the transition from print to electronic serial collections: A new model for academic chemistry libraries? Journal of the American Society for Information Science and Technology, 54, 1141-1148.

Connell, T. H., Rogers, S. A., \& Diedrichs, C. P. (2005). OhioLINK electronic journal use at Ohio State. Portal: Libraries and the Academy, 5, 371-390. 
Davis, P. M. (2004). Information-seeking behavior of chemists: A transaction log analysis of referral URLs. Journal of the American Society for Information Science and Technology, 55, 326-332.

De Groote, S. L., \& Dorsch, J.L. (2001). Online journals: Impact on print journal usage. Bulletin of the Medical Library Association, 89, 372-378.

De Groote, S. L., Shultz, M., \& Doranski, M. (2005). Online journals' impact on the citation patterns of medical faculty. Journal of the Medical Library Association, 93, 223-228.

De Groote, S. L. (2008). Citation patterns of online and print journals in the digital age. Journal of the Medical Library Association, 96, 362-369.

Dilek-Kayaoglu, H. (2008). Use of electronic journals by faculty at Istanbul university, Turkey: The results of a survey. Journal of Academic Librarianship, 34, 239-247.

Eason, K., Richardson, S., \& Yu, L. (2000). Patterns of use of electronic journals. Journal of Documentation, 56, 447-504.

Eason, K., Yu, L., \& Harker, S. (2000). The use and usefulness of functions in electronic journals: The experience of the SuperJournal Project. Program, 34, 1-28.

Fidel, R. (2008). Are we there yet?: Mixed methods research in library and information science. Library and Information Science Research, 30, 265-272.

King, D. W., \& Tenopir, C. (1999). Using and reading scholarly literature. Annual Review of Information Science and Technology, 34, 423-477.

Martell, C. (2008). The absent user: Physical use of academic library collections and services continues to decline 1995-2006. Journal of Academic Librarianship, 34, 400407.

Meho, L. I. (2006). E-Mail interviewing in qualitative research: A methodological discussion. Journal of the American Society for Information Science and Technology, 57, 1284-1295.

Nicholas, D., Huntington, P., \& Watkinson, A. (2005a). Scholarly journal usage: The results of deep log analysis. Journal of Documentation, 61, 248-280.

Nicholas, D., Huntington, P., Dobrowolski, T., Rowlands, I., Jamali, H. R., \& Polydoratou, P. (2005b). Revisiting 'obsolescence' and journal article 'decay' through usage data: An analysis of digital journal use by year of publication. Information Processing and Management, 41, 1441-1461.

Nicholas, D., Huntington, P., Monopoli, M., \& Watkinson, A. (2006a). Engaging with scholarly digital libraries (publisher platforms): The extent to which 'added-value' functions are used. Information Processing and Management, 42, 826-842. 
Nicholas, D., Huntington, P., Jamali, H. R., \& Tenopir, C. (2006b). Finding information in (very large) digital libraries: A deep log approach to determining differences in use according to method of access. Journal of Academic Librarianship, 32, 119-126.

Nicholas, D., Huntington, P., \& Jamali, H. R. (2007). The use, users, and role of abstracts in the digital scholarly environment. Journal of Academic Librarianship, 33, 446-453.

Nicholas, D., Huntington, P., Jamali, H. R., Rowlands, I., Dobrowolski, T., \& Tenopir, C. (2008). Viewing and reading behaviour in a virtual environment: The full-text download and what can be read into it. Aslib Proceedings: New Information Perspectives, 60, 185-198.

Rowlands, I. (2007). Electronic journals and user behaviour: A review of recent research. Library \& Information Science Research, 29, 369-396.

Siebenberg, T. R., Galbraith, B., \& Brady, E. E. (2004). Print versus electronic journal use in three Sci/Tech disciplines: What's going on here? College \& Research Libraries, 65, 427-438.

Tenopir, C., \& King, D. W. (2002). Towards electronic journals: Realities for scientists, librarians, and publishers. Washington, D.C.: Special Libraries Association.

Tenopir, C. (2003). Use and users of electronic library resources: an overview and analysis of recent research studies. Washington, DC: Council on Library and Information Resources. Retrieved December 10, 2008, from: http://www.clir.org/pubs/reports/pub120/pub120.pdf.

Tenopir, C., \& King, D.W (2008). Electronic journals and changes in scholarly article seeking and reading patterns. D-Lib Magazine, 14. Retrieved December 10, 2008, from: http://www.dlib.org/dlib/november08/tenopir/11tenopir.html.

Urbano, C., Anglada, L., Borrego, A., Cantos, C., Cosculluela, A., \& Comellas, N. (2004). The use of consortially purchased electronic journals by the CBUC (20002003). D-Lib Magazine, 10. Retrieved December 10, 2008, from: http://www.dlib.org/dlib/june04/anglada/06anglada.html.

Vaughan, K. T. L. (2003). Changing use patterns of print journals in the digital age: Impacts of electronic equivalents on print chemistry journal use. Journal of the American Society for Information Science and Technology, 54, 1149-1152.

Voorbij, H., \& Ongering, H. (2006). The use of electronic journals by Dutch researchers: A descriptive and exploratory study. Journal of Academic Librarianship, 32, 223-237. 